\title{
TMARg, a Novel Anthraquinone Isolated from Rubia cordifolia Nakai, Increases Osteogenesis and Mineralization through BMP2 and $\beta$-Catenin Signaling
}

\author{
Kyung-Ran Park ${ }^{1}$, Joon Yeop Lee ${ }^{2}$, Bo-Mi Kim ${ }^{2}$, Sang Wook Kang ${ }^{1, *}$ and Hyung-Mun Yun ${ }^{1, *}$ \\ 1 Department of Oral and Maxillofacial Pathology, School of Dentistry, Kyung Hee University, \\ Seoul 02447, Korea; rudfks282@naver.com \\ 2 National Institute for Korean Medicine Development, Gyeongsan 38540, Korea; \\ choo19090@nikom.or.kr (J.Y.L.); bom0203@nikom.or.kr (B.-M.K.) \\ * Correspondence: pathemis@khu.ac.kr (S.W.K.); yunhm@khu.ac.kr (H.-M.Y.); Tel.: +82-02-961-0691; \\ Fax: +82-02-960-1457 (S.W.K. \& H.-M.Y.)
}

Received: 17 June 2020; Accepted: 22 July 2020; Published: 27 July 2020

\begin{abstract}
Background: Plant extracts have long been regarded as useful medicines in the treatment of human diseases. Rubia cordifolia Nakai has been used as a traditional medicine, as it has pharmacological properties such as antioxidant and anti-inflammatory activity. However, the biological functions of TMARg, isolated from the roots of R. cordifolia, in osteoblast differentiation remain unknown. This study was performed to investigate the pharmacological effects and intracellular signaling of TMARg in the osteoblast differentiation of pre-osteoblast MC3T3-E1 cells and mesenchymal precursor $\mathrm{C} 2 \mathrm{C} 12$ cells. Methods: Cell viability was evaluated using an MTT assay. Early and late osteoblast differentiation was examined by analyzing the activity of alkaline phosphatase (ALP), and by staining it with Alizarin red S (ARS). Cell migration was determined by using migration assays. Western blot analysis and immunocytochemical analysis were used to examine the intracellular signaling pathways and differentiation proteins. Results: In the present study, TMARg showed no cytotoxicity and increased the osteoblast differentiation in pre-osteoblasts, as assessed from the alkaline phosphate (ALP) staining and activity and ARS staining. TMARg also induced BMP2 expression and increased the $p$-smad1/5/8-RUNX2 and $\beta$-catenin pathways in both MC3T3-E1 and C2C12 cells. Furthermore, TMARg activated mitogen-activated protein kinases (MAPKs) and increased the cell migration rate. In addition, the TMARg-mediated osteoblast differentiation was suppressed by BMP and Wnt inhibitors with the downregulation of BMP2 expression. Conclusion: These findings demonstrate that TMARg exerts pharmacological and biological effects on osteoblast differentiation through the activation of BMP2 and $\beta$-catenin signaling pathways, and suggest that TMARg might be a potential phytomedicine for the treatment of bone diseases.
\end{abstract}

Keywords: phytomedicine; Rubia cordifolia Nakai; TMARg; osteoblast; BMP2; $\beta$-catenin

\section{Introduction}

Rubia cordifolia Nakai is a flowering plant species from the family of coffee (Rubiaceae), and the roots of the plant have drawn considerable attention as an important medicine due to their potent pharmacological properties, including anti-inflammatory, neuroprotective, anti-oxidant, hepatoprotective, and anti-diabetic properties [1-5]. The roots of the Rubiaceae family plants have also been used as sources of anthraquinones [6]. The derivatives of 1,3,6-trihydroxy-2-methylanthraquinone were only found in 
some forms of R. cordifolia [7]. It was reported that anthraquinone derivatives from Morinda officinalis have antiosteoporotic effects in vivo $>$, and that emodin, an anthraquinone derivative from the roots and bark of the genus Rhamnus, and anthraquinone glycoside aloin induced osteogenic initiation of MC3T3-E1 cells in vitro [8-10]. Our group has isolated 1,3,6-trihydroxy-2-methyl-9,10-anthraquinone-3-O-(6'-O-acetyl)$\alpha$-L-hamnopyranosyl-( $(\rightarrow 2)-\beta$-D-glucopyranoside (TMARg) from the roots of $R$. cordifolia Nakai. However, its pharmacological effects in osteoblast lineages have not been defined yet.

Major bone diseases, such as osteoporosis and periodontitis, are characterized by abnormalities of bone formation. The defective and excessive bone formation is caused by dysfunctions in proliferation, migration, and differentiation of osteoblast lineages. Osteoblast lineages are specialized cells that were differentiated from mesenchymal stem cells (MSCs) [11]. Osteogenic growth factors, such as BMPs and Wnts, induce osteogenesis in MSCs, leading to bone formation with the synthesis of bone specific proteins and the mineralization of organic bone matrix [11-15]. In pharmacological approaches, such as the use of anabolic agents to stimulate bone formation, parathyroid hormone (PTH) therapy replaces the disadvantages of anti-resorptive agents, such as bisphosphonates and calcitonin $[10,16]$. However, PTH has limited availability due to being comparatively more expensive and has some other disadvantages associated with it. Therefore, regarding a pharmacological approach using natural compounds, anabolic agents that treat bone diseases, such as osteoporosis, periodontitis, and Paget's disease, have been identified.

In the present study, we examined the biological mechanisms and intracellular signaling of TMARg on osteogenesis in pre-osteoblast MC3T3-E1 cells and mesenchymal precursor C2C12 cells, using them as in vitro cell systems.

\section{Results}

\subsection{TMARg Has No Cytotoxicity Effects in Pre-Osteoblasts}

3,6-Trihydroxy-2-methyl-9,10-anthraquinone-3-O-(6'-O-acetyl)- $\alpha$-L-hamnopyranosyl-(1 $\rightarrow 2)$ $\beta$-D-glucopyranoside (TMARg) was isolated from the roots of $R$. cordifolia Nakai and the HPLC chromatogram and structure of TMARg are shown in Figure 1A,B. To test the cytotoxicity in pre-osteoblasts, TMARg $(0.1,1,10,30$, and $100 \mu \mathrm{M})$ was used for treatment of pre-osteoblast MC3T3-E1 cells and $\mathrm{C} 2 \mathrm{C} 12$ cells for $24 \mathrm{~h}$, and cell viability was investigated using an MTT assay. TMARg did not affect cytotoxicity in the cells (Figure 1C,D). For the next treatment experiments, concentrations of TMARg below $100 \mu \mathrm{M}$ were used.

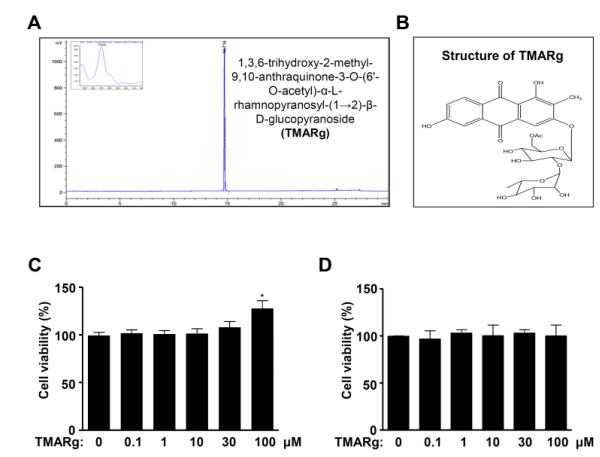

Figure 1. Effects of TMARg regarding cell toxicity in pre-osteoblasts. (A) HPLC chromatogram of 1,3,6-trihydroxy-2-methyl-9,10-anthraquinone-3-O-(6'-O-acetyl)- $\alpha$-L-rhamnopyranosyl-(1 $\rightarrow 2)-$ $\beta$-D-glucopyranoside (TMARg) isolated from the roots of Rubia cordifolia. (B) Chemical structure of TMARg. (C,D) TMARg was used for the treatment of pre-osteoblasts (C) and C2C12 (D) at concentrations of $0.1,1,10,30$, and $100 \mu \mathrm{M}$ for $24 \mathrm{~h}$. Cell viability was measured by using the MTT assay. The data are representative of the results of three independent experiments. Data represent the means \pm SEMs of the experiments. ${ }^{*}, p<0.05$ was considered significantly different compared to the control. 


\subsection{TMARg Increases the Staining and Activity of ALP during Osteogenesis of Pre-Osteoblasts}

To demonstrate the effects of TMARg on osteogenesis, we induced osteoblast differentiation in osteogenic supplement medium (OS) containing $50 \mu \mathrm{g} / \mathrm{mL}$ L-AA and $10 \mathrm{mM} \beta$-GP with TMARg. Osteoblast differentiation was observed by staining alkaline phosphatase (ALP); it was used as an early phase marker during osteogenesis, using a digital camera and a colorimetric detector. As shown in Figure 2A, TMARg increased ALP staining in a dose-dependent manner (Figure 2A). ALP-positively-stained cells were also observed using a light microscope (Figure 2B). Under the same conditions, the treatment of TMARg also significantly increased the ALP enzymatic activity in a dose-dependent manner, which was consistent with ALP staining (Figure 2C).

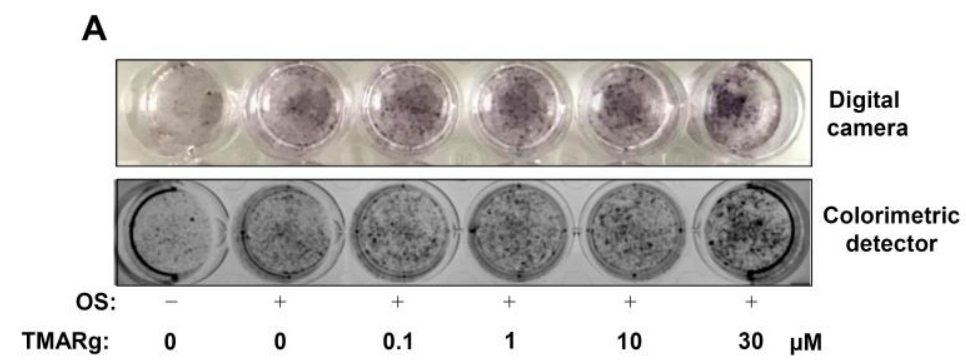

B

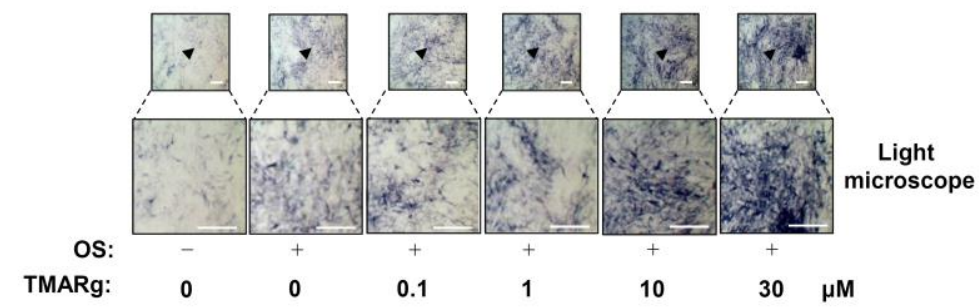

C

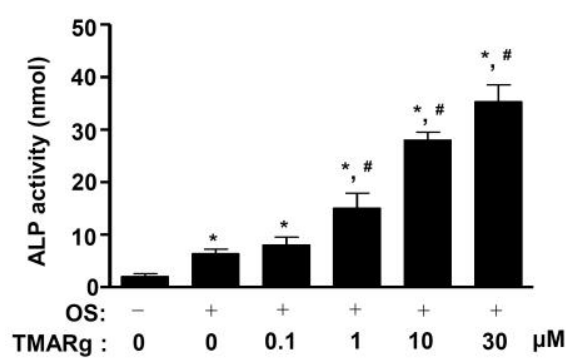

Figure 2. TMARg promotes early osteoblast differentiation. (A,B) Pre-osteoblasts were seeded onto 24-well plates $\left(2 \times 10^{4}\right.$ cells/well) and were cultured in osteogenic supplement medium (OS) containing $50 \mu \mathrm{g} / \mathrm{mL}$ L-AA and $10 \mathrm{mM} \beta$-GP in the absence or presence of TMARg $(0,0.1,1,10$, and $30 \mu \mathrm{M})$ for five days. The levels of ALP staining were detected using a digital camera (upper) and a colorimetric detector (bottom) (A). ALP-stained cells were observed by using a light microscope (bottom: magnified images). The arrowhead indicates the magnified region (B). (C) After the cells were seeded onto 48-well plates $\left(1 \times 10^{4}\right.$ cells/well), ALP activity was measured at $405 \mathrm{~nm}$ using the Multiskan GO Microplate Spectrophotometer. Scale bar: $100 \mu \mathrm{m}$. The data are representative of the results of three independent experiments. Data represent the means \pm SEMs of the experiments. ${ }^{*}, p<0.05$ was considered significantly different, compared to the control. \#, $p<0.05$ was considered significantly different, compared to the OS. 


\subsection{TMARg Increases Mineralized Nodule Formation during Osteogenesis of Pre-Osteoblasts}

In order to validate the effects of TMARg on osteogenesis, the late osteoblast differentiation was determined by using Alizarin red S (ARS) staining, to assess the degree of matrix mineralization using a scanner and colorimetric detector. A mineralized nodule was visually formed at 14 days, but not at seven days (Figure $3 \mathrm{~A}-\mathrm{C}$ ). At 14 days, TMARg increased the matrix mineralization in a dose-dependent manner (Figure 3B,C). To validate the effects of TMARg on late osteoblast differentiation, ARS staining was quantified, and the data significantly revealed the stimulatory effect of TMARg in a dose-dependent manner (Figure 3D).

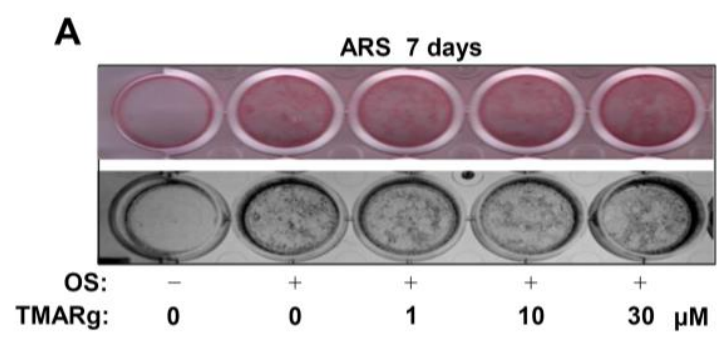

B
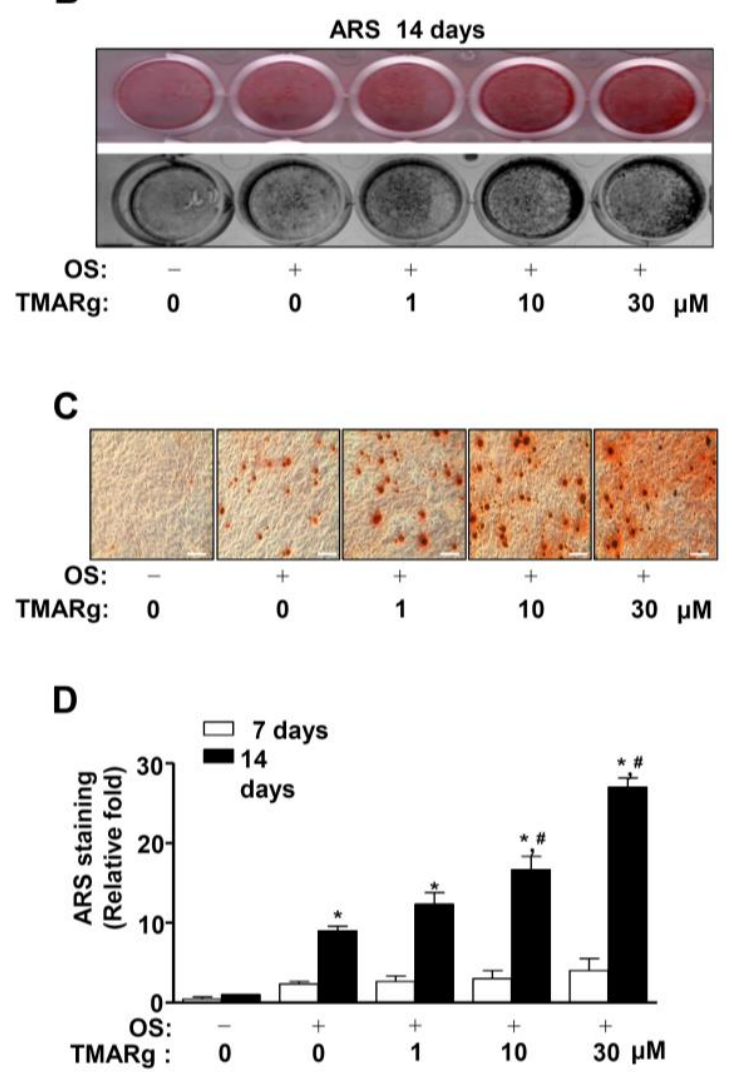

Figure 3. TMARg promotes late osteoblast differentiation. (A-D) Pre-osteoblasts were seeded onto 24-well plates and were cultured in OS with TMARg $(0,0.1,1,10$, and $30 \mu \mathrm{M})$. Mineralized nodule formation was assessed by using ARS staining at 7 (A) and 14 days (B). The levels of ARS staining were observed using a scanner (upper) and a colorimetric detector (bottom) (A,B). Mineralization nodules were observed by using a light microscope (C). Stains were eluted with DMSO to quantify the intensity of ARS staining, and this quantification was performed by using the Multiskan GO Microplate Spectrophotometer. The data are represented as relative fold-increases of the control (C). The data are representative of the results of three independent experiments. Scale bar: $100 \mu \mathrm{m}$. Data represent the means \pm SEMs of experiments. ${ }^{*}, p<0.05$ was considered significantly different, compared to the control. \#, $p<0.05$ was considered significantly different, compared to the OS. 
2.4. TMARg Activates BMP2-Smad1/5/8 and $\beta$-Catenin Signaling, and Increases RUNX2 Expression during Osteogenesis

To determine the biological mechanism underlying the effect of TMARg on osteogenesis, bone morphogenetic protein (BMP) signaling was examined in mesenchymal precursor and pre-osteoblast cells. TMARg significantly enhanced the expression of BMP2 and increased the phosphorylation of Smad1/5/8 protein and downstream signaling molecules of BMP2, and upregulated the expression of RUNX2, a BMP2 target gene, which is a key transcription factor that plays an essential role in osteoblast differentiation (Figure $4 \mathrm{~A}, \mathrm{~B}$ ). Next, we examined whether TMARg affects $\beta$-catenin signaling in osteogenesis. TMARg increased the phosphorylation of GSK3 $\beta$ and the levels of $\beta$-catenin in osteoblast differentiation, while TMARg did not affect the expression of Wnt3a. We further confirmed the expression of RUNX2 in the nucleus after the treatment with TMARg in mesenchymal precursor and pre-osteoblast cells, using immunocytochemistry. Immunofluorescence staining revealed that TMARg increased the nuclear expression of RUNX2 in osteoblast differentiation (Figure 5A,B).

A

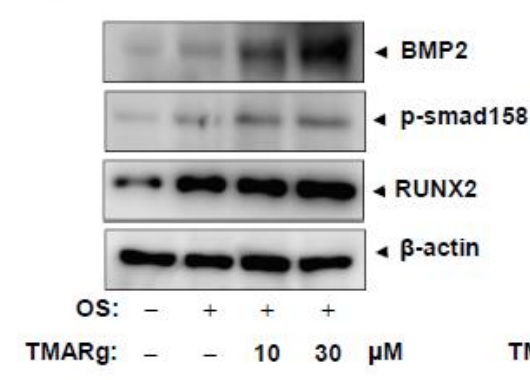

C

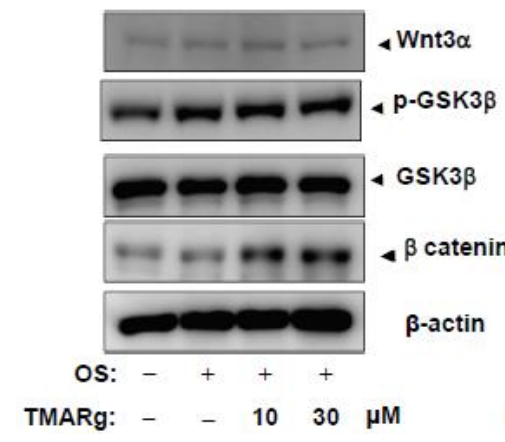

B

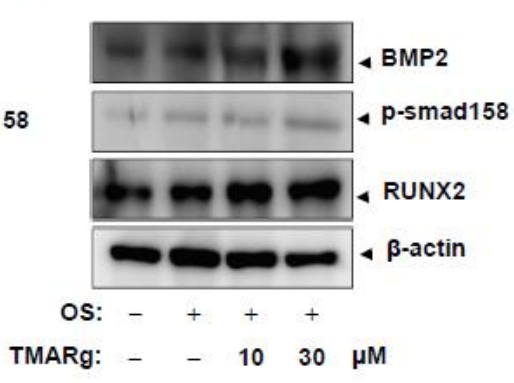

D

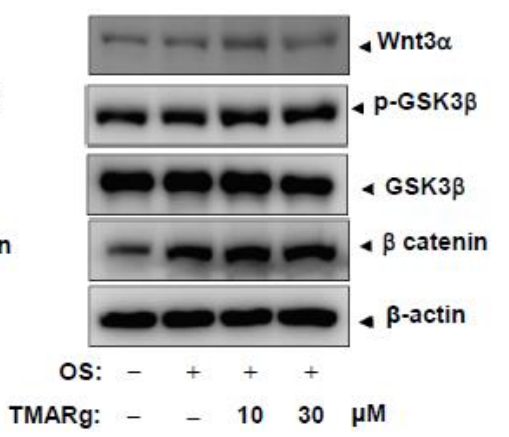

Figure 4. TMARg enhances intracellular BMP2 signaling and $\beta$-catenin in osteoblast differentiation. (A-D) Mesenchymal cells $(\mathbf{A}, \mathbf{C})$ and pre-osteoblasts $(\mathbf{B}, \mathbf{D})$ were cultured in OS with TMARg (10 and $30 \mu \mathrm{M})$ for $24 \mathrm{~h}$. BMP2, phospho-Smad1/5/8, RUNX2, and $\beta$-actin (A,B), and Wnt3a, phospho-GSK3 $\beta$, GSK3 $\beta, \beta$-catenin, and $\beta$-actin (C,D) were assessed by using Western blot analysis. $\beta$-actin was detected on the same sample to normalize the values obtained for the lysates. The data are representative of the results of three independent experiments. 

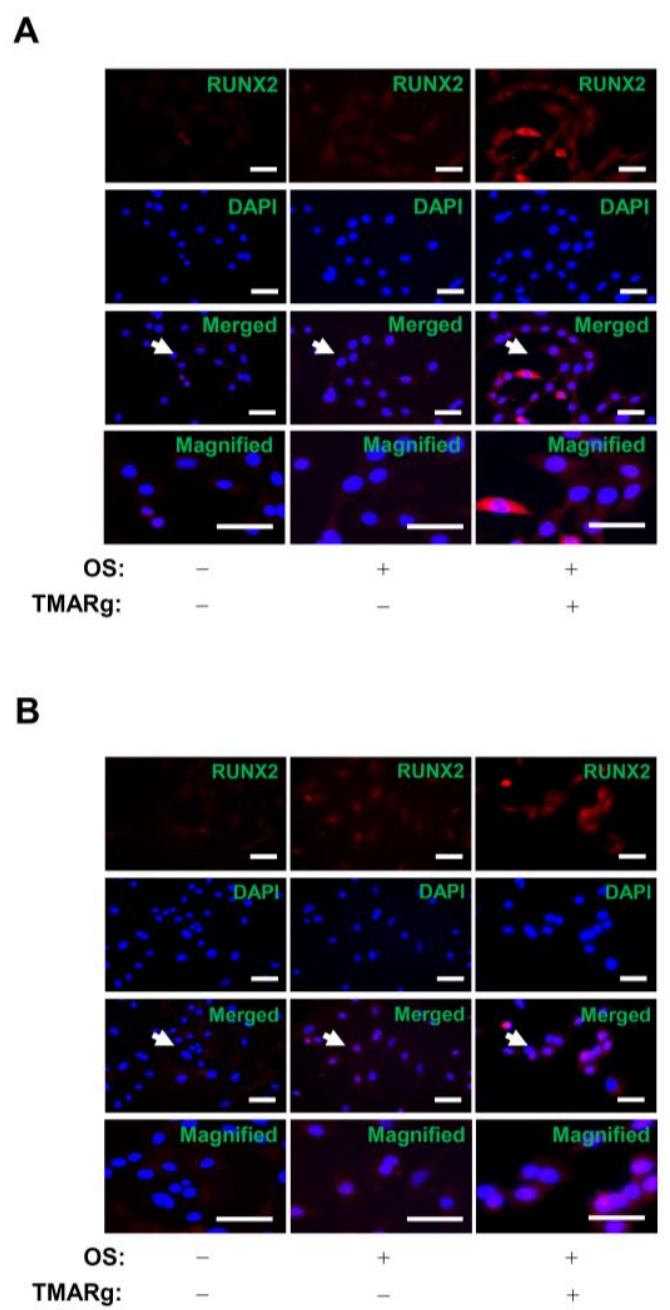

Figure 5. TMARg accumulates the expression of RUNX2 into the nucleus in osteoblast differentiation. $(\mathbf{A}, \mathbf{B})$ After mesenchymal cells (A) and pre-osteoblasts (B) were cultured in OS with TMARg $(30 \mu \mathrm{M})$ for $24 \mathrm{~h}$, the cells were fixed and permeabilized. RUNX2 was immunostained with rabbit anti-RUNX2 antibody, followed by Alexa-Fluor 568-conjugated secondary antibody (red). Then, the cells were counterstained with DAPI (blue). The third panel shows the merged images of the first and second panels. The bottom panels show the magnifications of the merged images. The arrow indicates the magnified region. Scale bar: $50 \mu \mathrm{m}$. The data are representative of the results of three independent experiments.

\subsection{TMARg Activates MAPKs and Increases Cell Migration during Osteogenesis}

We next examined whether mitogen-activated protein kinases (MAPKs) are involved in the regulation of TMARg-mediated osteoblast differentiation. The results showed that TMARg stimulates the phosphorylation of ERK1/2 in pre-osteoblast cells but not in mesenchymal precursor cells, while TMARg increased the activation of p38 in both pre-osteoblast and mesenchymal precursor cells (Figure 6A,B). To investigate whether TMARg affected the cell migration of pre-osteoblasts due to MAPKs, a wound healing migration assay was carried out. TMARg significantly enhanced the cell migration rate in a dose-dependent manner in mesenchymal precursor cells (Figure 6C,D). Pre-osteoblasts revealed a more evident increase than that of mesenchymal precursor cells (Figure 6E,F). 
A

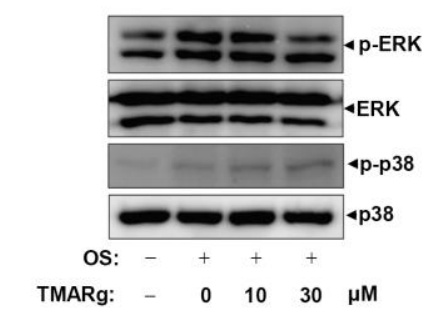

C
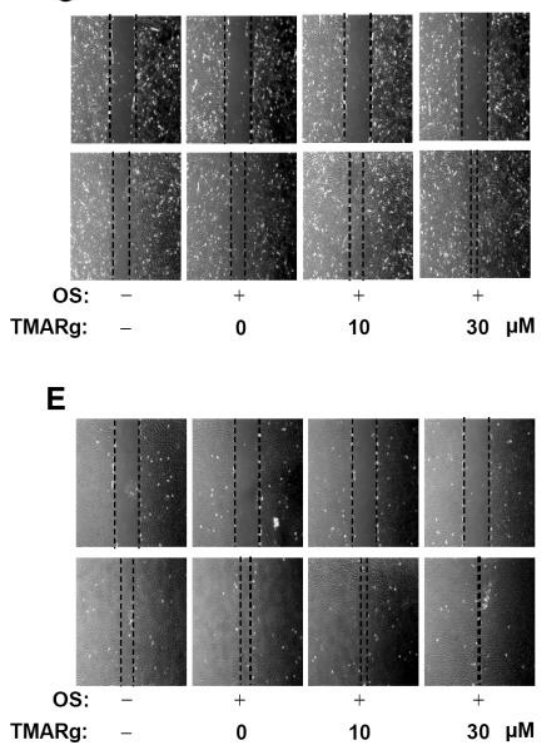

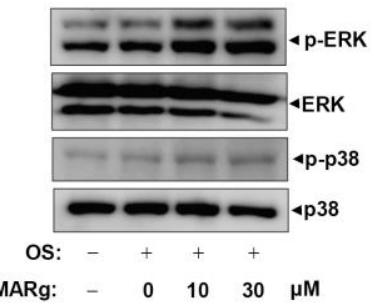

D

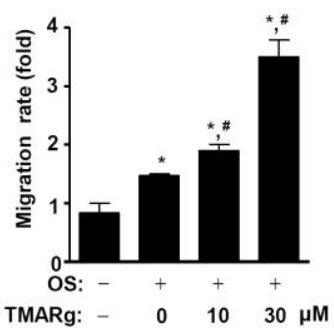

F

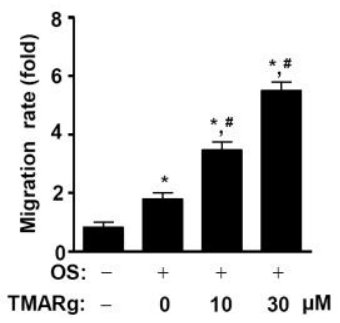

Figure 6. TMARg activates MAPKs signaling and promotes the cell migration rate in osteoblast differentiation. (A,B) After mesenchymal cells (A) and pre-osteoblasts (B) were cultured in OS with TMARg $(10$ and $30 \mu \mathrm{M})$ for $24 \mathrm{~h}$, phospho-ERK1/2, ERK1/2, phospho-p38, and p38 were analyzed using Western blot analysis. (C-F) Cell migration in mesenchymal cells (C,D) and pre-osteoblasts (E,F) was observed under a phase contrast microscope (C,E), and the cell migration rate (fold) was measured by the area enclosing the spreading cell population and expressed as a bar graph normalized to the control $(\mathbf{D}, \mathbf{F})$. The data are representative of the results of three independent experiments. Data represent the means \pm SEMs of experiments. ${ }^{*}, p<0.05$ was considered significantly different, compared to the control. \#, $p<0.05$ was considered significantly different, compared to the OS.

\subsection{TMARg Promotes Osteogenesis via the BMP2 and $\beta$-Catenin Pathways during Osteogenesis}

To investigate the functional consequence of the TMARg-mediated BMP2 and $\beta$-catenin pathways on osteogenesis, TMARg was treated in the presence or absence of BMP2 antagonist, noggin, and Wnt/ $\beta$-catenin signaling inhibitor Dickkopf-1 (Dkk-1). Results showed that the pretreatment of noggin significantly inhibited TMARg-induced ALP enzymatic activity and mineralized nodule formation, while the pretreatment of Dkk-1 only partially suppressed these (Figure 7A,B). Consistent with the preceding findings, noggin and Dkk-1 also attenuated the TMARg-stimulated BMP2 expression in osteoblast differentiation (Figure 7C). 
A

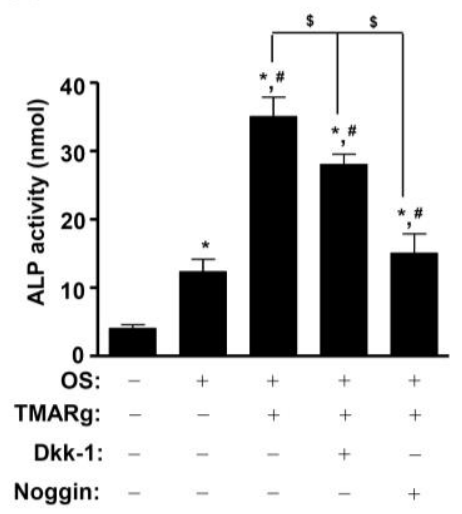

B

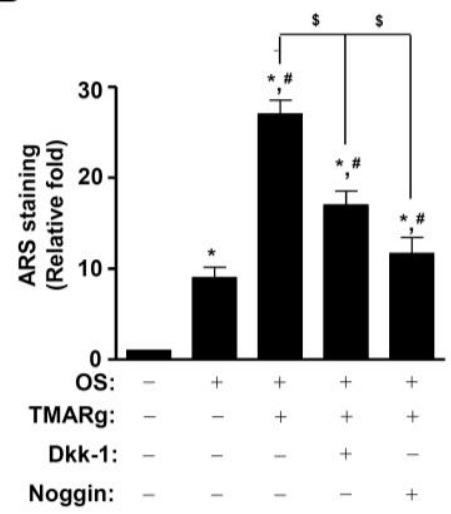

C
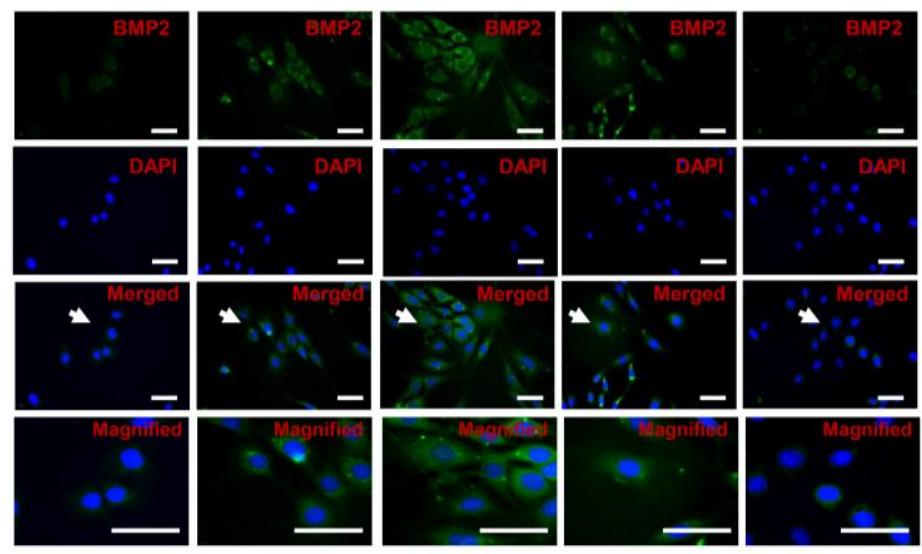

OS:
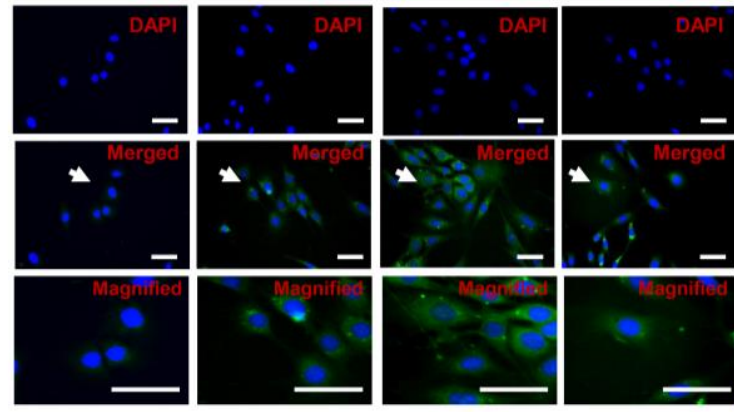

Dkk-1:

Noggin:

Figure 7. Inhibition of BMP2 and $\beta$-catenin signaling attenuates osteoblast differentiation using TMARg treatment. (A) The cells were seeded onto 48-well plates and were cultured in OS with TMARg $(30 \mu \mathrm{M})$ in the absence or presence of Dkk-1 $(0.5 \mu \mathrm{g} / \mathrm{mL})$ and noggin $(10 \mu \mathrm{g} / \mathrm{mL})$ for 5 days. ALP activity was measured by using ALP activity assays. (B) The cells were seeded onto 24-well plates and differentiated for 14 days. Mineralized nodule formation was assessed using ARS staining. (C) BMP2 was immunostained with rabbit anti-BMP2 antibody, followed by Alexa-Fluor 488-conjugated secondary antibody (green). Then, the cells were counterstained with DAPI (blue). The bottom panels show the magnification of the merged images. The arrow indicates the magnified region. Scale bar: $50 \mu \mathrm{m}$. The data are representative of the results of three independent experiments. Data represent the means \pm SEMs of experiments. ${ }^{*}, p<0.05$ was considered significantly different, compared to the control. \#, $p<0.05$ was considered significantly different, compared to the OS. $\$, p<0.05$ was considered significantly different, compared to the OS + TMARg.

\section{Discussion}

Many studies have demonstrated that natural compounds increase osteoblast differentiation through signaling pathways, transcription factors, and bone-specific proteins [17,18]. As anabolic agents, natural compounds have been identified to treat bone diseases, such as osteoporosis, periodontitis, and Paget's disease. $[19,20]$. In the present study, we first identified the efficacy of TMARg in osteoblast differentiation. The process of osteogenesis from mesenchymal cells and pre-osteoblasts is driven by a complex series of biological processes initiated by the migration of mesenchymal cells to bone formation sites and their subsequent proliferation, and lineage commitment into pre-osteoblasts, leading to the maturation of osteoblasts and the mineralization of the organic bone matrix [21,22]. If this 
process is abnormal, it leads to bone diseases, such as osteoporosis and periodontal disease [13-15]. In the early osteoblast differentiation, the expression of ALP is upregulated, which induces and regulates specific osteoblast genes. In late osteoblast differentiation, the extracellular bone matrix is mineralized by calcium deposition [23-25]. The present results revealed that TMARg-mediated osteoblast differentiation upregulated ALP expression and significantly enhanced its enzymatic activity; TMARg also increased mineralized nodule formation. These data suggest that TMARg induces early and late osteoblast differentiation of pre-osteoblasts.

BMP proteins have been known to stimulate osteogenesis and bone formation by inducing osteoblast differentiation [26,27]. BMP2 interacts with BMP receptor IA (BMPRIA) or BMPRIB, and BMPRII. BMP2-mediated BMPR signaling induces the phosphorylation of Smad1/5/8, the interaction between phosphorylated Smad1/5/8 and Smad4, the nuclear translocation of the complexes, and then the regulation of gene expression, such as that of the RUNX2 gene which is an essential transcription factor for osteoblast differentiation [28-30]. In the present study, TMARg increased the expression of BMP2 and the phosphorylation of Smad1/5/8, which was followed by the expression of RUNX2. The involvement of BMP2 in osteoblast differentiation and mineralization was also clarified by its inhibitor, noggin. It was also reported that ALP expression is upregulated by Smad1/5/8 and RUNX2 signaling in osteogenesis [31,32]. These data suggest that TMARg regulates the BMP2/Smad1/5/8 pathway in osteoblast differentiation.

$\beta$-catenin signaling is also the main mechanism of osteogenesis and bone formation [33]. In vitro and in vivo studies showed that the activation of the canonical $\mathrm{Wnt} / \beta$-catenin pathway promotes osteoblast differentiation and mineralization $[25,34-36]$. The canonical Wnt3a binds to Frizzled and LRP5/6 receptors, and induces the stabilization of cytoplasmic $\beta$-catenin by inhibiting GSK3 $\beta$ [37]. Consequently, $\beta$-catenin is accumulated in the cytoplasm and translocated into the nucleus to regulate gene transcription $[38,39]$. In the present study, TMARg increased the phosphorylation of GSK3 $\beta$ and the stabilization of $\beta$-catenin by inactivating GSK3 $\beta$. It was reported that $\beta$-catenin signaling increases BMP2 expression in mesenchymal cells and pre-osteoblasts, and also that RUNX2 integrates the BMP2 and Wnt $/ \beta$-catenin signaling pathways during osteogenesis [40-43]. In addition, our data revealed that Dkk-1 abolished TMARg-mediated osteoblast differentiation and BMP2 expression. These results suggest that TMARg induces the functional cross talk that integrates BMP2 and $\beta$-catenin and stimulates osteoblast differentiation and mineralization through the BMP2/Smad1/5/8 and $\mathrm{Wnt} / \beta$-catenin signaling pathways.

The non-canonical BMP2 signaling pathway also activates MAPKs, such as ERK1/2, p38, and JNK1/2 to regulate osteogenic transcription factors, such as RUNX2 [44,45], and proliferation and migration of mesenchymal cells and pre-osteoblasts [46-49]. In the present study, TMARg only increased the phosphorylation of p38 in mesenchymal cells, while TMARg increased the phosphorylation of ERK1/2 and p38 in pre-osteoblasts. This might be the difference in ERK1/2 activation in both mesenchymal cells and pre-osteoblasts, since mesenchymal cells are committed to actively proliferate into pre-osteoblasts and further differentiate into non-proliferating osteoblasts, to cause maturation and mineralization $[21,22,50]$. In the present study, TMARg promoted an increase in the cell migration rate that leads to osteoblast differentiation. Thus, our data suggest that TMARg promotes cell migration through MAPK signaling in mesenchymal cells and pre-osteoblasts.

In conclusion, we originally demonstrated that TMARg isolated from the roots of $R$. cordifolia stimulated osteoblast differentiation with increases in ALP activity, nodule formation, and migration through the BMP2 and $\beta$-catenin signaling pathways. Therefore, our findings provide novel evidence on the biological mechanisms of TMARg in osteogenesis that give rise to a great potential regarding the bone patho-physiology. TMARg may also be a phytotherapeutic compound that can be used to treat bone diseases, such as osteoporosis and periodontal disease. 


\section{Materials and Methods}

\subsection{Plant Material}

The stem bark of root of Rubia cordifolia Nakai was purchased from commercial herbal market, Daegu, Republic of Korea. The materials were confirmed taxonomically by Chong-Won Kim (College of Pharmacy, Catholic University of Daegu, Republic of Korea). A voucher specimen (CUDP 02001) has been deposited at the College of Pharmacy, Catholic University of Daegu.

\subsection{Extraction and Isolation of TMARg}

The dried roots of Rubia cordifolia Nakai (10 kg) were extracted with refluxed $100 \% \mathrm{MeOH}$ for $8 \mathrm{~h}$ $(500 \mathrm{~mL} \times 3)$. The $\mathrm{MeOH}$ extract $(1048.4 \mathrm{~g})$ was solvent partitioned with distilled water and EtOAc. The EtOAc soluble fraction (180 g) was applied to a silica gel column chromatography and eluted with a gradient $\mathrm{CH}_{2} \mathrm{Cl}_{2}$ and $\mathrm{MeOH}$ (25:1 to 6:1) to yield ten fractions (RCE 1-RCE 10). The fraction RCE 7 (1.3 g) was subjected to reversed phase column chromatography with 25\% aqueous $\mathrm{MeOH}$ to give active compound (301.1 mg). The chemical structure of active compound was identified as an anthraquinone, 1,3,6-trihydroxy-2-methyl-9,10-anthraquinone-3-O-(6'-O-acetyl)- $\alpha$-L-hamnopyranosyl$(1 \rightarrow 2)$ - $\beta$-D-glucopyranoside (TMARg).

\subsection{1,3,6-Trihydroxy-2-Methyl-9,10-Anthraquinone-3-O-(6'-O-Acetyl)- $\alpha$-L-Hamnopyranosyl-(1 $\rightarrow 2)-\beta$-D- Glucopyranoside (TMARg)}

Yellow powder; ESI-MS $m / z=621.2[\mathrm{M}+\mathrm{H}]^{+}$, molecular formula $\mathrm{C}_{29} \mathrm{H}_{32} \mathrm{O}_{15} ;{ }^{1} \mathrm{H}-\mathrm{NMR}(500 \mathrm{MHz}$, pyridine- $\left.d_{5}\right) \delta 8.37(1 \mathrm{H}, \mathrm{d}, J=8.4 \mathrm{~Hz}, \mathrm{H}-8), 8.05(1 \mathrm{H}, \mathrm{s}, \mathrm{H}-5), 7.93(1 \mathrm{H}, \mathrm{s}, \mathrm{H}-4), 7.46(1 \mathrm{H}, \mathrm{dd}, J=2.4,8.4 \mathrm{~Hz}$, H-7), $6.56\left(1 \mathrm{H}, \mathrm{s}, \mathrm{H}-1^{\prime}\right), 5.86\left(1 \mathrm{H}, \mathrm{d}, J=7.6 \mathrm{~Hz}, \mathrm{H}-1^{\prime \prime}\right), 2.58\left(3 \mathrm{H}, \mathrm{s}, \mathrm{COCH}_{3}\right), 2.07(3 \mathrm{H}, \mathrm{s}, \mathrm{H}-11), 1.73(3 \mathrm{H}$, s, H-6"); ${ }^{13} \mathrm{C}-\mathrm{NMR}(125 \mathrm{MHz}$, pyridine-d $) \delta 187.7$ (C-9), 183.2 (C-10), 171.5 (-COCCH 3$), 165.6(\mathrm{C}-6)$, 163.1 (C-1), 161.5 (C-3), 136.9 (C-10a), 133.3 (C-4a), 130.0 (C-8), 126.0 (C-8a), 122.5 (C-7), 122.4 (C-2), 114.3 (C-5), 112.1 (C-9a), $106.7(\mathrm{C}-4), 102.6\left(\mathrm{C}-1^{\prime \prime}\right), 99.6\left(\mathrm{C}-1^{\prime}\right), 79.6\left(\mathrm{C}-3^{\prime}\right), 78.1\left(\mathrm{C}-2^{\prime}\right), 76.1\left(\mathrm{C}-5^{\prime}\right)$, $74.6\left(\mathrm{C}-4^{\prime \prime}\right), 73.1\left(\mathrm{C}-2^{\prime \prime}\right), 73.0\left(\mathrm{C}-3^{\prime \prime}\right), 71.9\left(\mathrm{C}-4^{\prime}\right), 70.6\left(\mathrm{C}-5^{\prime \prime}\right), 64.8\left(\mathrm{C}-6^{\prime}\right), 21.2\left(-\mathrm{COCH}_{3}\right), 19.5\left(\mathrm{C}-6^{\prime \prime}\right)$, $9.9(\mathrm{C}-11)$.

\subsection{Nuclear Magnetic Resonance (NMR)}

Nuclear magnetic resonance (NMR) experiments were performed on a JEOL ECX-500 spectrometer $\left({ }^{1} \mathrm{H}, 500 \mathrm{MHz} ;{ }^{13} \mathrm{C}, 125 \mathrm{MHz}\right.$; JEOL Ltd., Japan). All chemical shifts were referenced relative to the corresponding signals $\left(\delta_{\mathrm{H}} 3.31 / \delta_{\mathrm{C}} 49.15\right.$ for $\left.\mathrm{CD}_{3} \mathrm{OD}\right)$. Electron ionization mass spectrometer (EI-MS) data were obtained using micromass spectrum (AUTOSPEC, UK). High performance liquid chromatography (HPLC) was performed using Agilent 1200 series (Agilent Technologies, CA, USA). Open column chromatography (CC) was carried out over a silica gel 60 (70-230 mesh, 230-400 mesh ASTM, Merck, Darmstadt, Germany) and sephadex LH-20 gel (GE Healthcare, Uppsala, Sweden). Pre-coated silica gel $60 \mathrm{~F}_{254}$ (Merck) were used for thin-layer chromatography (TLC).

\subsection{Culture of Pre-Osteoblast MC3T3E-1 Cells and Mesenchymal Precursor C2C12 Cells, and Osteoblast Differentiation}

Pre-osteoblast MC3T3E-1 cells (\#CRL-2593) purchased from the American Type Culture Collection (ATCC) (Manassas, VA, USA) were kindly provided by the Bioevaluation Center (Korea Research Institute of Bioscience and Biotechnology, Republic of Korea). The cells were cultured in $\alpha$-minimum essential medium ( $\alpha$-MEM) without L-ascorbic acid (WELGEME, Inc., Repubic of Korea) supplemented with $10 \%$ fetal bovine serum (FBS), penicillin (100 units $/ \mathrm{mL})$, and streptomycin $(100 \mu \mathrm{g} / \mathrm{mL})$ at $37^{\circ} \mathrm{C}$ in a humidified atmosphere of $5 \% \mathrm{CO}_{2}$ and $95 \%$ air. Osteoblast differentiation was induced by changing to osteogenic supplement medium (OS) containing $50 \mu \mathrm{g} / \mathrm{mL}$ L-ascorbic acid (L-AA) and $10 \mathrm{mM}$ $\beta$-glycerophosphate ( $\beta$-GP) (Sigma-Aldrich, St. Louis, MO, USA). The medium was replaced every 2 days during the incubation period. Mesenchymal precursor C2C12 cells (\#CRL 1722, ATCC, Manassas, 
VA) kindly provided from Dr. Ki Choon Choi (National Institute of Animal Science, Republic of Korea) were cultured in DMEM (Gibco BRL, Grand Island, NY) supplemented with 10\% FBS, penicillin (100 units $/ \mathrm{mL})$, and streptomycin $(100 \mu \mathrm{g} / \mathrm{mL})$ at $37^{\circ} \mathrm{C}$ in a humidified atmosphere of $5 \% \mathrm{CO}_{2}$ and $95 \%$ air. Osteoblast differentiation was induced by changing to OS containing $50 \mu \mathrm{g} / \mathrm{mL} \mathrm{L}-\mathrm{AA}$ and $10 \mathrm{mM} \beta$-GP (Sigma-Aldrich, St. Louis, MO) with recombinant BMP2 (100 ng/mL) (R\&D Systems, Minneapolis, MN). The medium was replaced every 2 days during the incubation period. TMARg was dissolved in $100 \%$ DMSO, and the stock solution is diluted at 1:1000. A final concentration of $0.1 \%$ DMSO was used as the control.

\subsection{MTT Assay}

Cell viability was measured using a 3-[4,5-dimethylthiazol-2-yl]-2,5-diphenyltetrazolium bromide (MTT) assay to detect NADH-dependent dehydrogenase activity, as previously described [51].

\subsection{Western Blot Analysis}

Western blot analysis was carried out as previously described [52]. Briefly, equal amounts of proteins $(20 \mu \mathrm{g})$ transferred to a polyvinylidene fluoride (PVDF) membrane (Millipore, Bedford, MA, USA) were blocked for $1 \mathrm{~h}$ at room temperature and incubated overnight at $4{ }^{\circ} \mathrm{C}$ with the primary antibodies. The membrane was incubated with diluted horseradish peroxidase (HRP)-conjugated secondary antibodies (1:10,000, Jackson ImmunoResearch, West Grove, PA) for $2 \mathrm{~h}$ at room temperature was treated with the enhanced chemiluminescence (ECL) kit (Millipore, Bedford, MA). The bound antibodies were detected using an enhanced chemiluminescence (ECL) kit and the ProteinSimple detection system (ProteinSimple Inc., Santa Clara, CA, USA).

\subsection{Cell Migration Assay}

Cell migration was accessed using an in vitro wound healing assay as previously described [53]. Briefly, the cells were wounded with a $200 \mu \mathrm{L}$ pipette tip and cultured in the absence and presence of TMARg $(10$, and $30 \mu \mathrm{M})$ for $24 \mathrm{~h}$ at $37^{\circ} \mathrm{C}$ in a humidified atmosphere of $5 \% \mathrm{CO}_{2}$ and $95 \%$ air. Cell migration was observed under light microscopy and cell migration rate was quantified.

\subsection{Alkaline Phosphatase (ALP) Staining Assay}

Cells were washed with $1 \times$ PBS and then fixed in 10\% formalin for $15 \mathrm{~min}$ at room temperature. After washing with distilled water, the cells were incubated with substrate solution for the reaction of ALP at $37^{\circ} \mathrm{C}$ for $1 \mathrm{~h}$, followed according to the manufacturer's protocol (Takara Bio Inc., Tokyo, Japan). The ALP staining was detected by a digital camera and colorimetric detector (ProteinSimple Inc., Santa Clara, CA, USA).

\subsection{ALP Activity Assay}

ALP activity was performed according to the manufacturer's protocol using alkaline phosphatase activity colorimetric assay kit (Biovision, Milpitas, CA, USA). The absorbance was measured at $405 \mathrm{~nm}$ using the Multiskan GO Microplate Spectrophotometer (Thermo Fisher Scientific, Waltham, MA, USA).

\subsection{Alizarin Red S (ARS) Staining}

Cells were fixed in $10 \%$ formalin for $15 \mathrm{~min}$ and rinsed with distilled water. Cells were stained with $2 \%$ Alizarin red S ( $\mathrm{pH} 4.2$ ) (Sigma-Aldrich) for $20 \mathrm{~min}$ with gentle agitation. The level of Alizarin red S staining was observed using a scanner and colorimetric detector (ProteinSimple Inc., Santa Clara, CA, USA). After scanning the stained wells, stains were dissolved in 100\% DMSO and the absorbance was measured at $590 \mathrm{~nm}$ using the Multiskan GO Microplate Spectrophotometer (Thermo Fisher Scientific). 


\subsection{Immunocytochemistry}

Cells were fixed with $10 \%$ formaline for $15 \mathrm{~min}$ at room temperature, permeabilized with $0.2 \%$ Triton X-100 in 1X PBS for 20 min, and blocked with 3\% BSA diluted in PBS for $1 \mathrm{~h}$ and incubated with the specific primary antibodies overnight at $4{ }^{\circ} \mathrm{C}$. Subsequently, the cells were incubated with an anti-rabbit secondary antibody labeled with Alexa-Fluor 488 or Alexa-Fluor 568 (1:500 dilution, Invitrogen, Carlsbad, CA) for $2 \mathrm{~h}$ at room temperature. Next, the cells were incubated with 4',6-diamidino-2-phenylindole (DAPI) (Sigma-Aldrich) for $10 \mathrm{~min}$ at room temperature. The cells were washed three times, mounted, and viewed on a confocal microscope (K1-Fluo Confocal Laser Scanning Microscope, Daejeon, Republic of Korea).

\subsection{Statistical Analysis}

The data were analyzed using Prism Version 5 program (GraphPad Software, Inc., San Diego, CA, USA). All numeric values are presented as the means \pm SEMs. The statistical significance of data was determined using a Student's unpaired $t$-test. A value of $p<0.05$ was considered to statistically significant.

Author Contributions: Conceptualization, K.-R.P. and H.-M.Y.; methodology, K.-R.P. and J.Y.L; software, K.-R.P.; validation, K.-R.P., S.W.K., and B.-M.K.; formal analysis, K.-R.P.; investigation, K.-R.P.; resources, B.-M.K., J.Y.L., and S.W.K.; data curation, K.-R.P.; writing—original draft preparation, K.-R.P.; writing—review and editing, S.W.K. and H.-M.Y.; visualization, K.-R.P.; supervision, H.-M.Y.; project administration, H.-M.Y.; funding acquisition, H.-M.Y. All authors have read and agreed to the published version of the manuscript.

Funding: This work was supported by the National Research Foundation of Korea (NRF) grant funded by the Korean government (MSIP) (NRF-2018R1D1A1B07043282).

Acknowledgments: We appreciate the Bioevaluation Center (Korea Research Institute of Bioscience and Biotechnology, Republic of Korea) for experimental assistance.

Conflicts of Interest: The authors declare no conflict of interest.

\section{Abbreviations}

$\begin{array}{ll}\text { ALP } & \text { Alkaline phosphatase } \\ \text { ARS } & \text { Alizarin red S } \\ \beta \text {-GP } & \beta \text {-glycerophosphate } \\ \text { L-AA } & \text { L-ascorbic acid } \\ \text { MAPKs } & \text { Mitogen-activated protein kinases } \\ \text { MSCs } & \text { Mesenchymal stem cells } \\ \text { MTT } & 3 \text {-[4,5-dimethylthiazol-2-yl]-2,5-diphenyltetrazolium bromide } \\ \text { OS } & \text { Osteogenic supplement } \\ \text { RUNX2 } & \text { Runt-related transcription factor } 2 \\ \text { TMARg } & 1,3,6 \text {-trihydroxy-2-methyl-9,10-anthraquinone-3-O-(6'-O-acetyl)- } \\ & \alpha \text {-L-hamnopyranosyl-(1-2)- } \beta \text {-D-glucopyranoside }\end{array}$

\section{References}

1. Ndhlala, A.R.; Finnie, J.F.; Van Staden, J. Plant composition, pharmacological properties and mutagenic evaluation of a commercial Zulu herbal mixture: Imbiza ephuzwato. J. Ethnopharmacol. 2011, 133, 663-674. [CrossRef]

2. Rawal, A.; Muddeshwar, M.; Biswas, S. Effect of Rubia cordifolia, Fagonia cretica linn, and Tinospora cordifolia on free radical generation and lipid peroxidation during oxygen-glucose deprivation in rat hippocampal slices. Biochem. Biophys. Res. Commun. 2004, 324, 588-596. [CrossRef]

3. Rawal, A.K.; Muddeshwar, M.G.; Biswas, S.K. Rubia cordifolia, Fagonia cretica linn and Tinospora cordifolia exert neuroprotection by modulating the antioxidant system in rat hippocampal slices subjected to oxygen glucose deprivation. BMC Complement. Altern. Med. 2004, 4, 11. [CrossRef] 
4. Shilpa, P.N.; Venkatabalasubramanian, S.; Devaraj, S.N. Ameliorative effect of methanol extract of Rubia cordifolia in N-nitrosodiethylamine-induced hepatocellular carcinoma. Pharm. Biol. 2012, 50, 376-383. [CrossRef] [PubMed]

5. Patil, R.A.; Jagdale, S.C.; Kasture, S.B. Antihyperglycemic, antistress and nootropic activity of roots of Rubia cordifolia Linn. Indian J. Exp. Biol. 2006, 44, 987-992. [PubMed]

6. Wan, X.S.; Xu, S.J.; Guo, X.Z.; Zhang, J. Pharmacognostical studies on the root of Rubia cordifolia var. pratensis Nakai and R. sylvatica Nakai. Zhong Yao Tong Bao 1988, 13, 7-9. [PubMed]

7. Jansen, P.C.M.; Plant Resources of Tropical Africa (Program). Dyes and Tannins; PROTA Foundation: Wageningen, The Netherlands, 2005; 215p.

8. Wu, Y.B.; Zheng, C.J.; Qin, L.P.; Sun, L.N.; Han, T.; Jiao, L.; Zhang, Q.Y.; Wu, J.Z. Antiosteoporotic activity of anthraquinones from Morinda officinalis on osteoblasts and osteoclasts. Molecules 2009, 14, 573-583. [CrossRef]

9. Lee, S.U.; Shin, H.K.; Min, Y.K.; Kim, S.H. Emodin accelerates osteoblast differentiation through phosphatidylinositol 3-kinase activation and bone morphogenetic protein-2 gene expression. Int. Immunopharmacol. 2008, 8, 741-747. [CrossRef]

10. Pengjam, Y.; Madhyastha, H.; Madhyastha, R.; Yamaguchi, Y.; Nakajima, Y.; Maruyama, M. Anthraquinone Glycoside Aloin Induces Osteogenic Initiation of MC3T3-E1 Cells: Involvement of MAPK Mediated Wnt and Bmp Signaling. Biomol. Ther. (Seoul) 2016, 24, 123-131. [CrossRef]

11. Fakhry, M.; Hamade, E.; Badran, B.; Buchet, R.; Magne, D. Molecular mechanisms of mesenchymal stem cell differentiation towards osteoblasts. World J. Stem Cells 2013, 5, 136-148. [CrossRef]

12. Bonewald, L.F. The amazing osteocyte. J. Bone Miner. Res. 2011, 26, 229-238. [CrossRef] [PubMed]

13. Karsenty, G.; Kronenberg, H.M.; Settembre, C. Genetic control of bone formation. Annu. Rev. Cell Dev. Biol. 2009, 25, 629-648. [CrossRef]

14. Zheng, X.; Dai, J.; Zhang, H.; Ge, Z. MicroRNA-221 promotes cell proliferation, migration, and differentiation by regulation of ZFPM2 in osteoblasts. Braz. J. Med. Biol. Res. 2018, 51, e7574. [CrossRef]

15. Karsenty, G.; Wagner, E.F. Reaching a genetic and molecular understanding of skeletal development. Dev. Cell 2002, 2, 389-406. [CrossRef]

16. Reid, I.R. Short-term and long-term effects of osteoporosis therapies. Nat. Rev. Endocrinol. 2015, 11, 418-428. [CrossRef]

17. An, J.; Yang, H.; Zhang, Q.; Liu, C.; Zhao, J.; Zhang, L.; Chen, B. Natural products for treatment of osteoporosis: The effects and mechanisms on promoting osteoblast-mediated bone formation. Life Sci. 2016, 147, 46-58. [CrossRef] [PubMed]

18. Soelaiman, I.N.; Das, S.; Shuid, A.N.; Mo, H.; Mohamed, N. Use of medicinal plants and natural products for treatment of osteoporosis and its complications. Evid. Based Complement. Altern. Med. 2013, 2013, 764701. [CrossRef] [PubMed]

19. Mishra, B.B.; Tiwari, V.K. Natural products: An evolving role in future drug discovery. Eur. J. Med. Chem. 2011, 46, 4769-4807. [CrossRef]

20. Dias, D.A.; Urban, S.; Roessner, U. A historical overview of natural products in drug discovery. Metabolites 2012, 2, 303-336. [CrossRef]

21. Infante, A.; Rodriguez, C.I. Osteogenesis and aging: Lessons from mesenchymal stem cells. Stem Cell Res. Ther. 2018, 9, 244. [CrossRef]

22. Granero-Molto, F.; Weis, J.A.; Miga, M.I.; Landis, B.; Myers, T.J.; O’Rear, L.; Longobardi, L.; Jansen, E.D.; Mortlock, D.P.; Spagnoli, A. Regenerative effects of transplanted mesenchymal stem cells in fracture healing. Stem Cells 2009, 27, 1887-1898. [CrossRef] [PubMed]

23. Guntur, A.R.; Rosen, C.J. The skeleton: A multi-functional complex organ: New insights into osteoblasts and their role in bone formation: The central role of PI3Kinase. J. Endocrinol. 2011, 211, 123-130. [CrossRef] [PubMed]

24. Lee, H.S.; Jung, E.Y.; Bae, S.H.; Kwon, K.H.; Kim, J.M.; Suh, H.J. Stimulation of osteoblastic differentiation and mineralization in MC3T3-E1 cells by yeast hydrolysate. Phytother. Res. 2011, 25, 716-723. [CrossRef] [PubMed]

25. Kim, M.B.; Song, Y.; Hwang, J.K. Kirenol stimulates osteoblast differentiation through activation of the BMP and Wnt/beta-catenin signaling pathways in MC3T3-E1 cells. Fitoterapia 2014, 98, 59-65. [CrossRef] 
26. Katagiri, T.; Yamaguchi, A.; Komaki, M.; Abe, E.; Takahashi, N.; Ikeda, T.; Rosen, V.; Wozney, J.M.; Fujisawa-Sehara, A.; Suda, T. Bone morphogenetic protein-2 converts the differentiation pathway of $\mathrm{C} 2 \mathrm{C} 12$ myoblasts into the osteoblast lineage. J. Cell Biol. 1994, 127, 1755-1766. [CrossRef]

27. Wozney, J.M.; Rosen, V.; Celeste, A.J.; Mitsock, L.M.; Whitters, M.J.; Kriz, R.W.; Hewick, R.M.; Wang, E.A. Novel regulators of bone formation: Molecular clones and activities. Science 1988, 242, 1528-1534. [CrossRef]

28. Canalis, E.; Economides, A.N.; Gazzerro, E. Bone morphogenetic proteins, their antagonists, and the skeleton. Endocr. Rev. 2003, 24, 218-235. [CrossRef]

29. Miyazono, K.; Kamiya, Y.; Morikawa, M. Bone morphogenetic protein receptors and signal transduction. J. Biochem. 2010, 147, 35-51. [CrossRef]

30. Lee, M.H.; Kim, Y.J.; Kim, H.J.; Park, H.D.; Kang, A.R.; Kyung, H.M.; Sung, J.H.; Wozney, J.M.; Ryoo, H.M. BMP-2-induced Runx2 expression is mediated by Dlx5, and TGF-beta 1 opposes the BMP-2-induced osteoblast differentiation by suppression of Dlx5 expression. J. Biol. Chem. 2003, 278, 34387-34394. [CrossRef]

31. Gaur, T.; Lengner, C.J.; Hovhannisyan, H.; Bhat, R.A.; Bodine, P.V.; Komm, B.S.; Javed, A.; van Wijnen, A.J.; Stein, J.L.; Stein, G.S.; et al. Canonical WNT signaling promotes osteogenesis by directly stimulating Runx2 gene expression. J. Biol. Chem. 2005, 280, 33132-33140. [CrossRef]

32. Phimphilai, M.; Zhao, Z.; Boules, H.; Roca, H.; Franceschi, R.T. BMP signaling is required for RUNX2-dependent induction of the osteoblast phenotype. J. Bone Miner. Res. 2006, 21, 637-646. [CrossRef] [PubMed]

33. Krishnan, V.; Bryant, H.U.; Macdougald, O.A. Regulation of bone mass by Wnt signaling. J. Clin. Investig. 2006, 116, 1202-1209. [CrossRef] [PubMed]

34. Lo, Y.C.; Chang, Y.H.; Wei, B.L.; Huang, Y.L.; Chiou, W.F. Betulinic acid stimulates the differentiation and mineralization of osteoblastic MC3T3-E1 cells: Involvement of BMP/Runx2 and beta-catenin signals. J. Agric. Food Chem. 2010, 58, 6643-6649. [CrossRef] [PubMed]

35. Bodine, P.V.; Komm, B.S. Wnt signaling and osteoblastogenesis. Rev. Endocr. Metab. Disord. 2006, 7, 33-39. [CrossRef]

36. Qiu, W.; Andersen, T.E.; Bollerslev, J.; Mandrup, S.; Abdallah, B.M.; Kassem, M. Patients with high bone mass phenotype exhibit enhanced osteoblast differentiation and inhibition of adipogenesis of human mesenchymal stem cells. J. Bone Miner. Res. 2007, 22, 1720-1731. [CrossRef]

37. MacDonald, B.T.; He, X. Frizzled and LRP5/6 receptors for Wnt/beta-catenin signaling. Cold Spring Harb. Perspect. Biol. 2012, 4, a007880. [CrossRef]

38. Reya, T.; Clevers, H. Wnt signalling in stem cells and cancer. Nature 2005, 434, 843-850. [CrossRef]

39. Moon, R.T.; Bowerman, B.; Boutros, M.; Perrimon, N. The promise and perils of Wnt signaling through beta-catenin. Science 2002, 296, 1644-1646. [CrossRef]

40. Rawadi, G.; Vayssiere, B.; Dunn, F.; Baron, R.; Roman-Roman, S. BMP-2 controls alkaline phosphatase expression and osteoblast mineralization by a Wnt autocrine loop. J. Bone Miner. Res. 2003, 18, 1842-1853. [CrossRef]

41. Fukuda, T.; Kokabu, S.; Ohte, S.; Sasanuma, H.; Kanomata, K.; Yoneyama, K.; Kato, H.; Akita, M.; Oda, H.; Katagiri, T. Canonical Wnts and BMPs cooperatively induce osteoblastic differentiation through a GSK3beta-dependent and beta-catenin-independent mechanism. Differentiation 2010, 80, 46-52. [CrossRef]

42. Zhang, R.; Oyajobi, B.O.; Harris, S.E.; Chen, D.; Tsao, C.; Deng, H.W.; Zhao, M. Wnt/ $\beta$-catenin signaling activates bone morphogenetic protein 2 expression in osteoblasts. Bone 2013, 52, 145-156. [CrossRef]

43. Zhang, J.F.; Li, G.; Chan, C.Y.; Meng, C.L.; Lin, M.C.; Chen, Y.C.; He, M.L.; Leung, P.C.; Kung, H.F. Flavonoids of Herba Epimedii regulate osteogenesis of human mesenchymal stem cells through BMP and Wnt/beta-catenin signaling pathway. Mol. Cell. Endocrinol. 2010, 314, 70-74. [CrossRef] [PubMed]

44. Huang, R.L.; Yuan, Y.; Tu, J.; Zou, G.M.; Li, Q. Opposing TNF- $\alpha /$ IL-1 $\beta$ - and BMP-2-activated MAPK signaling pathways converge on Runx2 to regulate BMP-2-induced osteoblastic differentiation. Cell Death Dis. 2014, 5, e1187. [CrossRef] [PubMed]

45. Chen, G.; Deng, C.; Li, Y.P. TGF-beta and BMP signaling in osteoblast differentiation and bone formation. Int. J. Biol. Sci. 2012, 8, 272-288. [CrossRef] [PubMed]

46. Westhoff, M.A.; Serrels, B.; Fincham, V.J.; Frame, M.C.; Carragher, N.O. SRC-mediated phosphorylation of focal adhesion kinase couples actin and adhesion dynamics to survival signaling. Mol. Cell. Biol. 2004, 24, 8113-8133. [CrossRef] [PubMed] 
47. Chang, Y.M.; Shih, Y.T.; Chen, Y.S.; Liu, C.L.; Fang, W.K.; Tsai, C.H.; Tsai, F.J.; Kuo, W.W.; Lai, T.Y.; Huang, C.Y. Schwann Cell Migration Induced by Earthworm Extract via Activation of PAs and MMP2/9 Mediated through ERK1/2 and p38. Evid. Based Complement. Altern. Med. 2011, 2011, 395458. [CrossRef]

48. Chen, Y.Y.; Liu, F.C.; Chou, P.Y.; Chien, Y.C.; Chang, W.S.; Huang, G.J.; Wu, C.H.; Sheu, M.J. Ethanol extracts of fruiting bodies of Antrodia cinnamomea suppress CL1-5 human lung adenocarcinoma cells migration by inhibiting matrix metalloproteinase-2/9 through ERK, JNK, p38, and PI3K/Akt signaling pathways. Evid. Based Complement. Altern. Med. 2012, 2012, 378415. [CrossRef]

49. Liao, X.; Lu, S.; Zhuo, Y.; Winter, C.; Xu, W.; Wang, Y. Visualization of Src and FAK activity during the differentiation process from HMSCs to osteoblasts. PLoS ONE 2012, 7, e42709. [CrossRef]

50. Da Silva Meirelles, L.; Chagastelles, P.C.; Nardi, N.B. Mesenchymal stem cells reside in virtually all post-natal organs and tissues. J. Cell Sci. 2006, 119, 2204-2213. [CrossRef]

51. Park, K.R.; Yun, H.M. RANKL-induced osteoclastogenesis in bone marrow-derived macrophages is suppressed by cisapride. Toxicology 2019, 422, 95-101. [CrossRef]

52. Park, K.R.; Kim, E.C.; Hong, J.T.; Yun, H.M. Dysregulation of 5-hydroxytryptamine 6 receptor accelerates maturation of bone-resorbing osteoclasts and induces bone loss. Theranostics 2018, 8, 3087-3098. [CrossRef] [PubMed]

53. Sequeira, D.B.; Seabra, C.M.; Palma, P.J.; Cardoso, A.L.; Peca, J.; Santos, J.M. Effects of a New Bioceramic Material on Human Apical Papilla Cells. J. Funct. Biomater. 2018, 9, 74. [CrossRef] [PubMed]

(C) 2020 by the authors. Licensee MDPI, Basel, Switzerland. This article is an open access article distributed under the terms and conditions of the Creative Commons Attribution (CC BY) license (http://creativecommons.org/licenses/by/4.0/). 